Original article

\title{
Severe cardiac phenotype of Berardinelli-Seip congenital lipodystrophy in an infant with homozygous E189X BSCL2 mutation
}

\author{
B. Friguls ${ }^{a}$, W. Coroleu ${ }^{a}$, R. del Alcazar ${ }^{a}$, P. Hilbert $^{b}$, L. Van Maldergem $^{\text {b,* }}{ }^{\text {, G. Pintos-Morell }}{ }^{\mathrm{a}}$ \\ a Department of Paediatrics, "Germans Trias i Pujol" Hospital, Badalona, Autonomous University of Barcelona, Spain \\ ${ }^{\mathrm{b}}$ Centre de Génétique Humaine, Institut de Pathologie et de Génétique, Gosselies, Belgium
}

\section{A R T I C L E I N F O}

\section{Article history:}

Received 2 March 2008

Accepted 26 October 2008

Available online 12 November 2008

\section{Keywords:}

Berardinelli-Seip congenital lipodystrophy Insulin resistance

Hypertrophic cardiomyopathy

Leptin

\begin{abstract}
A B S T R A C T
Berardinelli-Seip congenital lipodystrophy (BSCL) is a rare autosomal recessive condition associating insulin resistance, absence of subcutaneous fat and muscular hypertrophy. Disease-causing mutations have been described in AGPAT2 and BSCL2 genes. Hypertrophic cardiomyopathy is a classical late (third decade) complication which has only been occasionally described in childhood. We report on a 4-month -old Chinese male infant who presented with a severe BSCL "cardiac" phenotype comprising heart failure, hypertension and hypertrophic cardiomyopathy.
\end{abstract}

(c) 2008 Elsevier Masson SAS. All rights reserved.

\section{Introduction}

Berardinelli-Seip congenital lipodystrophy (BSCL) is a rare autosomal recessive metabolic disorder usually presenting at birth or in early infancy with lipoatrophy, acromegaloid features, lack of subcutaneous fat and hypertriglyceridemia. Clinical course comprises progressive insulin resistance leading to diabetes usually in the second decade of life. Because of the absence of functional adipocytes, lipid is stored in other tissues, including muscle and liver. The syndrome was first reported by Berardinelli in 1954 [1] and described in greater detail by Seip in 1959 [2]. After identification of disease-causing mutations in two genes located in 9q34 and 11q13 (AGPAT2 and BSCL2) [3,4], patients were described worldwide. Little information is available about putative alterations of these genes in Asian subjects. A series of patients in Japan [5] and recently one case in China [6] presenting BSCL2 mutations have been described. We report a Chinese male infant with an early onset and a severe phenotype carrying a BSCL2 mutation.

\subsection{Case report}

A 4-month-old male infant, born to unrelated Chinese parents, was hospitalized because of polypnea. On admission he presented: respiratory rate: $67 / \mathrm{min}$, Hb saturation: $97 \%$, heart rate: $200 / \mathrm{min}$,

\footnotetext{
* Corresponding author. Present address: Centre de Génétique Humaine, Université de Liège, Domaine universitaire du Sart-Tilman, 4000 Liège, Belgium.

E-mail address: vmald@skypro.be (L. Van Maldergem).
}

blood pressure: $150 / 60 \mathrm{mmHg}$ (SBP was $40 \mathrm{mmHg}$ over the 95th percentile for age and gender, DBP was on the 75th percentile) and had abundant sweating. The infant had a peculiar phenotype. The hair was dry and thick. Hirsutism was noticed in the face (with low frontal hairline), trunk and limbs. Hands and feet were enlarged (acromegaloid features) (Fig. 1a). Lipoatrophy affecting trunk, limbs, bottom and face with empty cheeks was observed (Fig. 1b), together with prominent muscles and veins. A 3/6 heart murmur was heard in the apex. Abdominal distension with marked hepatomegaly was noted.

Laboratory results indicating profound metabolic changes at admission compared to follow-up are shown in Table 1. Serum leptin was not detectable. His bone age was significantly advanced. Abdominal ultrasound revealed an enlarged liver with homogeneously increased echogenicity indicating severe steatosis. The pancreas was hyperechogenic by sonography but the abdominal CT showed no pancreatic collections or necrosis. The echocardiogram displayed left ventricular hypertrophy, the septum (IVS: $11 \mathrm{~mm}, \mathrm{NV}$ for his BSA: $4.5-5.5 \mathrm{~mm}$ ) more than the posterior wall (LVPW: $6 \mathrm{~mm}, \mathrm{NV}: 4-5 \mathrm{~mm}$ ), with a ratio of 1.83 (Fig. 2a). This classified him as having severe asymmetrical septal hypertrophy (ASH), as ASH is defined as a ratio $\geq 1.4$. Doppler study showed a maximum gradient of the left ventricle outflow tract of $99.6 \mathrm{mmHg}$ indicating the presence of an obstructive dynamic pattern at mesoventricular level (Fig. 2b). In conclusion, the cardiac ultrasound exam with Doppler-colour showed a severe obstructive and asymmetrical septal hypertrophic cardiomyopathy (Fig. 3).

Clinical diagnosis of Berardinelli-Seip syndrome was confirmed by the identification of a stop codon in BSCL2 using molecular 


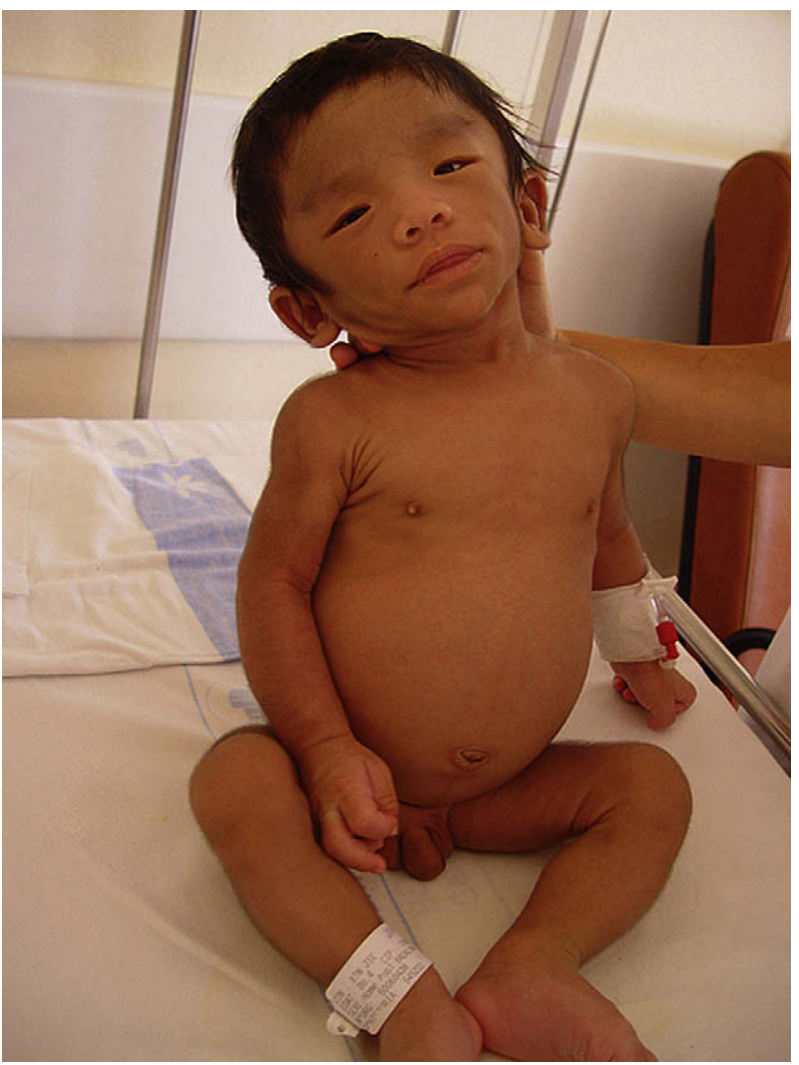

Fig. 1. Physical appearance at an age of 4 months. (a) Triangular face, micrognatia, enlarged tongue, low implanted ears and empty cheeks. (b) Lipoatrophy affecting trunk and bottom, with prominent muscles.

genetic testing as described by Magré et al. [4]. The patient was found to be homozygous for the mutation c.565G $>$ T or p.E189X in exon 5. Both parents were heterozygous for the same mutation. The p.E189X is a nonsense mutation replacing a glutamic acid residue by premature stop codon at position 189 leading to the formation of a truncated seipin protein. The patient had a normal 46XY karyotype.

With the diagnosis of pancreatitis (serum lipase $477 \mathrm{U} / \mathrm{L}$ ), we initiated parenteral nutrition containing: $14 \mathrm{~g} / \mathrm{kg} /$ day carbohydrates, $2 \mathrm{~g} / \mathrm{kg} /$ day proteins, $2.5 \mathrm{~g} / \mathrm{kg} /$ day lipids (with the minimum amount of essential fatty acids and MCT). After 15 days the analytical parameters improved (lipase $393 \mathrm{U} / \mathrm{L}$, triglycerides $5.3 \mathrm{mmol} / \mathrm{L}$ ), then an oral formula (Monogen ${ }^{\circledR}$ : containing $90 \%$ MCT, 10\% LCT) was introduced using standard dilution (17.5\%) in 6 regular meals adjusting the caloric need for age. After 2 months with the dietetic treatment a reduction of serum glucose, insulin

Table 1

Main laboratory results at first hospitalization and during follow-up.

\begin{tabular}{lllll}
\hline & $\begin{array}{l}\text { At } \\
\text { diagnosis }\end{array}$ & $\begin{array}{l}\text { 2 Months } \\
\text { after diagnosis }\end{array}$ & $\begin{array}{l}\text { 2 Years } \\
\text { after diagnosis }\end{array}$ & $\begin{array}{l}\text { Normal } \\
\text { values }\end{array}$ \\
\hline Glucose (mmol/l) & 12.2 & 4.2 & 4.5 & $3.8-5.6$ \\
Triglycerides (mmol/l) & 31.9 & 5.2 & 0.9 & $0.4-2.0$ \\
Cholesterol (mmol/l) & 5.01 & 5.7 & 4.1 & $1.4-4.4$ \\
Lipase (U/l) & 477 & 349 & 372 & $<200$ \\
Amilase (U/l) & 6 & 13 & 56 & $30-122$ \\
Insulin (mu.int./l) & 249 & 19.9 & 9.3 & $2.6-25$ \\
HbA1c \% & 3.5 & & 5.2 & $<5.8 \%$ \\
C-peptide (pmol/l) & 4038 & & 2.52 & $364-1655$ \\
AST (U/l) & 97 & 65 & 40 & $5-35$ \\
ALT (U/l) & 117 & 70 & 58 & $5-43$ \\
GGT (U/l) & 213 & 108 & 55 & $11-85$ \\
\hline
\end{tabular}

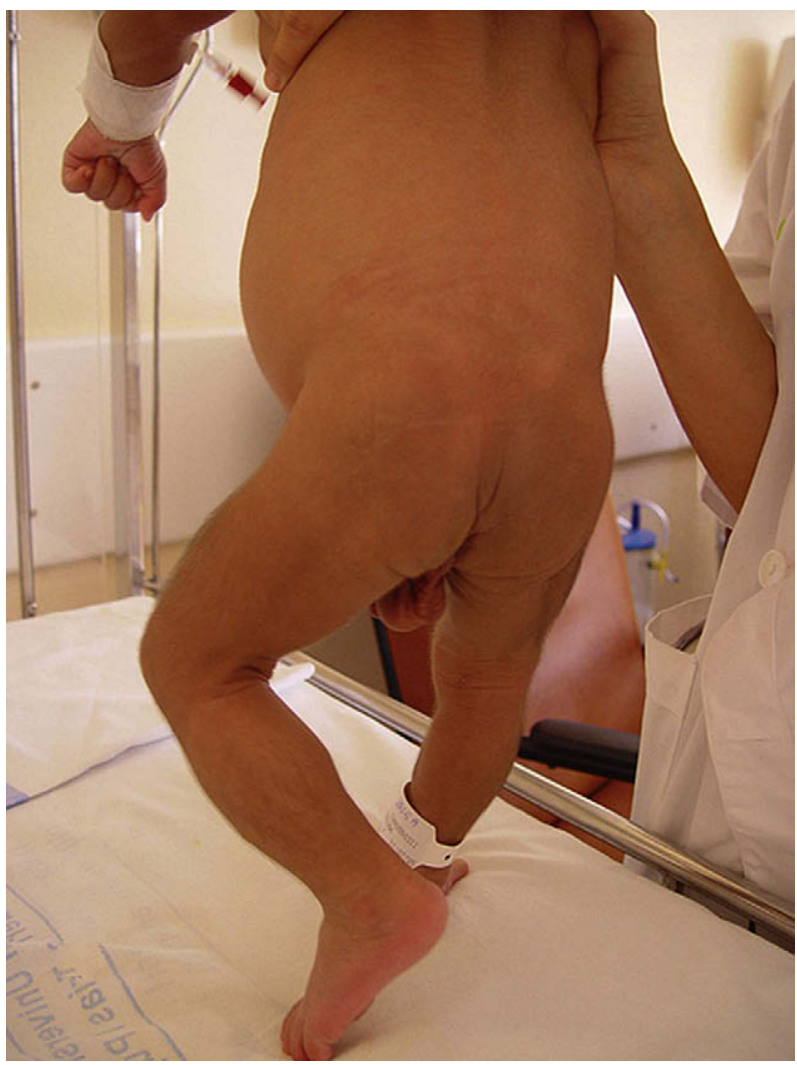

Fig. 2. (a) Cardiomyopathy with asymmetrical septal hypertrophy (IVS $=11 \mathrm{~mm}$ ). (b) Doppler study showed the presence of an obstructive dynamic pattern of the left ventricle outflow tract (maximum gradient: $99.6 \mathrm{mmHg}$ ).

and triglycerides was observed and liver enzyme levels were almost normalized (Table 1). The cardiac failure and the high blood pressure were controlled with oral propranolol solution (dose $2 \mathrm{mg} / \mathrm{kg} /$ day). The haemodynamic parameters improved in 4 weeks, presenting after this time a blood pressure of $100 / 50 \mathrm{mmHg}$ and a heart rate 120 per min. The hyperinsulinemia with hyperglycemia was easily corrected with the dietary treatment, but the $\mathrm{HbA1c}$ is progressively increasing suggesting a possible prediabetes status.

After 2-year follow-up period no more complications have been detected. He is currently presenting normal values, returned rapidly to normal range (Table 1 ), has a blood pressure of $130 / 80$

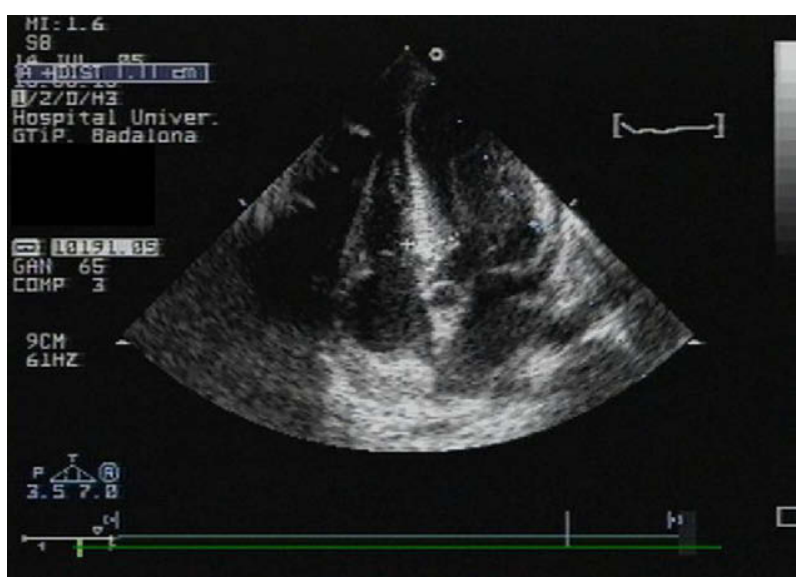

Fig. 3. 
(parents withdraw beta-blocker treatment), no arrhythmias has been detected, and the IVS is measuring $12.5 \mathrm{~mm}$ thick (NV for his BSA: 5-7). The maximum gradient of the left outflow tract detected is $14 \mathrm{mmHg}$ at rest.

\section{Discussion}

It is unusual to have major complications early in life in patients with BSCL. In our case, the triad of major diagnostic criteria (lipoatrophy, acromegaloid features, hypertriglyceridemia) lead to the diagnosis of BSCL at the early age of 4 months. In addition he presented life-threatening complications such as systemic arterial hypertension, hypertrophic cardiomyopathy with heart failure and pancreatitis. These major complications are only occasionally reported in infants with BSCL, although they were previously described in older patients. The pE189X mutation seems particularly harmful taking into account the early onset presentation with a severe cardiac affection and a poor prognosis. The only other case reported having the same mutation, is a 7 -year-old Chinese child presenting early onset diabetes, liver cirrhosis and left ventricle hypertrophy [6]. One can speculate on the putative deleterious nature of the pE189X mutation identified. As described, BSCL patients are homozygous or compound heterozygous, and most of the BSCL2 mutations are nonsense or frameshift mutations that are expected to cause loss of function of the protein [7].

Acute pancreatitis, presumably secondary to hypertriglyceridemia has been already reported in a 7-year-old female [7] and in a 17year-old male [8].

Cardiac involvement in CGL has been reported in the literature [9-15] but there are no cases describing early onset cardiac failure, as in our case. Bjornstad et al. [9] reported 6 cases of BSCL presenting myocardial hypertrophy, and Rheuban et al. [10] described 4 other similar cases. The average age at diagnosis in Bjornstad's series, confirmed by Rheuban was 20 years. A single case with an early onset hypertrophic cardiomyopathy has been reported in a Portuguese child who had evidence of ventricular hypertrophy at the age of 6 months, but she was not symptomatic until the age of 10 years [11]. The mechanism causing hypertrophic cardiomyopathy in patients with genetic insulin resistance syndrome as BSCL, and therefore with hyperinsulinemia, may result from the insulin action in the receptors of Insulin-like growth factor I (IGF-1) present in the myocardial tissue [10,12]. This is based on the occurrence of myocardial hypertrophy in children of diabetic mothers [13]. Hypertension was also present in a few patients with BSCL and myocardial hypertrophy at second or third decade of life $[10,15]$.
In summary, we present a male infant with severe BSCL expression, early in life, harboring the pE189X seipin gene truncating mutation. We emphasize the extremely severe cardiovascular manifestation in this infant, with systemic hypertension and hypertrophic cardiomyopathy leading to cardiac failure. Thus, the p.E189X mutation in BSCL may be associated with serious cardiovascular alterations beginning very early in life.

\section{References}

[1] W. Berardinelli, An undiagnosed endocrinometabolic syndrome: report of two cases, J. Clin. Endocrinol. Metab. 14 (1954) 193-204.

[2] M. Seip, Lipoatrophy and gigantism with associated endocrine manifestations: a new diencephalic syndrome? Acta Paediatr. Scand. 48 (1959) 555-574.

[3] A. Garg, R. Wilson, R. Barnes, E. Arioglu, Z. Zaidi, F. Gurakan, N. Kocak, S. O'Rahilly, S.I. Taylor, S.B. Patel, A.M. Bowcock, A gene for congenital generalized lipodystrophy maps to human chromosome 9q34, J. Clin. Endocrinol. Metab. 84 (1999) 3390-3394.

[4] J. Magré, M. Delepine, E. Khallouf, T. Gedde-Dahl Jr., L. Van Maldergem, E. Sobel, J. Papp, M. Meier, A. Megarbane, BSCL Working Group, M. Lathrop, $\mathrm{J}$. Capeau, Identification of the gene altered in Berardinelli-Seip congenital lipodystrophy on chromosome 11q13, Nat. Genet. 28 (2001) 365-370.

[5] K. Ebihara, T. Kusakabe, H. Masuzaki, N. Kobayashi, T. Tanaka, H. Chusho, F. Miyanaga, T. Miyazawa, T. Hayashi, K. Hosoda, Y. Ogawa, K. Nakao, Gene and phenotype analysis of congenital generalized lipodystrophy in Japanese: a novel homozygous nonsense mutation in seipin gene, J. Clin. Endocrinol. Metab. 89 (5) (2004) 2360-2364.

[6] J. Jing, C. Lingfeng, Z. Zhuhui, S. Shuixian, K. Wieland, Z. Dijing, Y. Rong, C. Ruoqian, C. Lian, Y. Yi, L. Feihong, Novel BSCL2 gene mutation E189X in Chinese congenital generalized lipodystrophy child with early onset diabetes mellitus, Eur. J. Endocrinol. 157 (2007) 783-787.

[7] L. Van Maldergem, J. Magre, T.E. Khallouf, T. Gedde-Dahl Jr., M. Delepine, O. Trygstad, E. Seemanova, T. Stephenson, C.S. Albott, F. Bonnici, V.R. Panz, J.-L. Medina, et al., Genotype-phenotype relationships in Berardinelli-Seip congenital lipodystrophy, J. Med. Genet. 39 (2002) 722-733.

[8] P. Figueiredo, A. Costa, R. Diamante, C. Cunha, R. Norton, J. Lamounier, E. Leao, Congenital generalized lipodystrophy, J. Pediatr. 80 (2004) 333-336.

[9] P.G. Bjornstad, B.K. Semb, O. Trygstad, M. Seip, Echocardiographic assessment of cardiac function and morphology in patients with generalised lipodystrophy, Eur. J. Pediatr. 144 (4) (1985) 355-359.

[10] K.S. Rheuban, R.M. Blizzard, M. Parker, T. Carter, T. Wilson, H.P. Gutgesell, Hypertrophic cardiomyopathy in total lipodystrophy, J. Pediatr. 109 (1986) 301-302.

[11] V.M. Bhayana, S.I. Joubert, C.L. Clarson, H. Cao, R.A. Hegele, Cardiomyopathy in congenital complete lipodystrophy, Clin. Genet. 61 (2002) 283-287.

[12] M.E. Geffner, T.V. Santulli, A.S. Kaplan, Hypertrophic cardiomyopathy in total lipodystrophy: insulin action in the face of insulin resistance? J. Pediatr. 110 (1) (1987) 161.

[13] J.A. Breitweser, R.A. Meyer, M.A. Sperling, R.C. Tsang, S. Kaplan, Cardiac septal hypertrophy in hyperinsulinemic infants, J. Pediatr. 96 (1980) 535-539.

[14] P.G. Bjornstad, A. Foerster, H. Ihlen, Cardiac findings in generalized lipodystrophy, Acta Paediatr. Suppl. 413 (1996) 39-43.

[15] R.F.M. Viegas, R.V.Z. Diniz, T.M.R.F. Viegas, E.B. Lira, D.R. de Almeida, Cardiac involvement in total generalized lipodystrophy, Arq. Bras. Cardiol. (2000) 301-302. 